\section{SYNTHESIS}

Synthesis

ISSN: 0328-1205

ISSN: 1851-779X

revistasynthesis@gmail.com

Universidad Nacional de La Plata

Argentina

\title{
IX JORNADAS DE ESTUDIOS CLÁSICOS Y MEDIEVALES "DIÁLOGOS CULTURALES" El tiempo en la literatura antigua y medieval: Orígenes, Ciclos, Edades
}

\author{
Zamperetti Martín, Deidamia Sofía \\ IX JORNADAS DE ESTUDIOS CLÁSICOS Y MEDIEVALES "DIÁLOGOS CULTURALES" EI tiempo en la \\ literatura antigua y medieval: Orígenes, Ciclos, Edades \\ Synthesis, vol. 26, núm. 2, 2019 \\ Universidad Nacional de La Plata, Argentina \\ Disponible en: http://www.redalyc.org/articulo.oa?id=84662943011 \\ DOI: https://doi.org/10.24215/1851779Xe068
}

Esta obra está bajo una Licencia Creative Commons Atribución-NoComercial-Compartirlgual 4.0 Internacional. 


\section{JORNADAS DE ESTUDIOS CLÁSICOS Y MEDIEVALES “DIÁLOGOS CULTURALES” El tiempo en la literatura antigua y medieval: Origenes, Ciclos,} Edades

Deidamia Sofia Zamperetti Martín

Universidad Nacional de La Plata, Argentina
DOI: https://doi.org/10.24215/1851779Xe068

Redalyc: http://www.redalyc.org/articulo.oa?id=84662943011

En la Facultad de Humanidades y Ciencias de la Educación de la Universidad Nacional de La Plata, durante los días 28, 29 y 30 de agosto de 2019, tuvo lugar la novena edición de las distinguidas Jornadas de Estudios Clásicos y Medievales "Diálogos Culturales” organizadas por el Centro de Estudios Latinos (integrado al IdIHCS-UNLP/Conicet), en colaboración con la Cátedra de Literatura Española Medieval y con el auspicio de las Secretarías de Posgrado y de Investigación de la Facultad de Humanidades y Ciencias de la Educación de la UNLP.

En esta oportunidad, la temática propuesta se circunscribió en torno a "el tiempo en la Antigüedad y el Medioevo: orígenes, ciclos, edades"; sin embargo, como en otras ocasiones, se admitió la participación con trabajos sobre otros temas relativos a Grecia y Roma, Proyecciones de la cultura griega en el Mediterráneo, Aspectos de la cultura romana, Diálogos entre Oriente y Occidente, Diálogos intertextuales en la literatura latina, La literatura española y/o Los textos medievales en diálogo con la antigüedad clásica y La tradición clásica en la literatura europea y americana, entre otros.

Las modalidades de participación de este evento que convoca a estudiosos de la cultura antigua y medieval fueron: conferencias, paneles, cursos y sesiones de comisiones, estas últimas con más de un centenar de participantes, la mayor parte de ellos con ponencias libres, pero también hubo foros de investigadores y "workshop" de alumnos. En esta ocasión se presentó como novedad la realización de un concurso literario de poesía y cuento destinado a estudiantes de la carrera de Letras de las Universidades e Institutos del profesorado del país con el objetivo de estimular la escritura creativa a partir de los temas propuestos en las Jornadas.

Por la mañana del miércoles 28, luego de la instancia de Acreditación, se dio comienzo al Acto de Apertura con la Conferencia Inaugural "Time in Senecan Tragedy" a cargo de Robert John Sklenar de la Universidad de Tennessee Knoxville de Estados Unidos. A continuación se disfrutó del brindis de recepción y se reanudaron las actividades con la primera Sesión de comisiones y, luego, se desarrollaron simultáneamente tres paneles: uno sobre Literatura Española Medieval "Temporalidades en la literatura medieval y renacentista” donde participaron Santiago Disalvo, Gloria Chicote, Martín Calabrese y Ely di Croce, todos ellos investigadores del IdIHCS (UNLP-Conicet); otro sobre Antigüedad Tardía "Conversión, convivencia y conflicto religioso en la Antigüedad Tardía” con la presencia de Esteban Noce (UBAConicet), Rodrigo Laham Cohen (UBA-Conicet), Mariano Splendido (UNLP-Conicet) y Darío Sánchez (IEH-Conicet) y, el tercero, sobre Literaturas Comparadas "Tiempo, eternidad y melancolía. Una mirada desde las literaturas europeas comparadas" donde expusieron sus trabajos Claudia Fernández Speier, Claudia Moronell y Graciela Wamba, pertenecientes al IdIHCS (UNLP-Conicet). El primer día de actividades finalizó con una segunda Sesión de comisiones donde expusieron sus trabajos quince docentes e investigadores del país.

El día jueves 29 se inició con dos Sesiones de comisiones, cada una con cuatro mesas de exposición en simultáneo. Alrededor del mediodía, la Dra. Florencia Calvo (UBA-Conicet) impartió su conferencia 
"Polifemo, Orfeo y Filomena. La voz de los poetas y el mundo clásico en la España de los siglos XVI y XVII". A partir de las 14 hs. se desarrollaron dos cursos en forma paralela: "The Augustan Character of Goethe's Römische Elegien” a cargo del Prof. Robert John Sklenar (Universidad de Tennessee Knoxville) y “Texto y música en la lírica gallego-portuguesa medieval: edición, reconstrucción e interpretación” proporcionado por la Dra. Gimena del Río (UBA-IIBICRIT, Conicet).

A continuación se presentaron tres Paneles simultáneos: el Panel de Literatura Latina Clásica y el de Literatura Griega Clásica, ambos constituidos por investigadores pertenecientes al IdIHCS (UNLPConicet), "El tiempo en la literatura latina" donde expusieron Lía Galán, María Delia Buisel, Guillermina Bogdan y Martín Vizzotti; y "Percepciones de la temporalidad en la Literatura Griega Clásica” con Graciela Zecchin, Juan Tobías Nápoli y Claudia Fernández. Además, se desarrolló el Panel de Literatura Europea Medieval "Tiempos de caballeros, damas y peregrinos en la Edad Media Europea" con la presencia de Lidia Amor (IMHICIHU-Conicet-FFyL-UBA), María Dumas (FFyL-UBA), Ana Basarte (UBA-UNSAM) y María Cristina Balestrini (FFyL-UBA).

El segundo día de actividades concluyó con la conferencia "Erotismos romanos. Virgilio erótico en las voces de Petronio y Ausonio" del Dr. Rubén Florio (UNS) y, de inmediato, se disfrutó del Vino de Honor convidado por los organizadores que propiciaron un grato y cálido ambiente.

El último día de las Jornadas contó con dos Sesiones de comisiones de lectura matutinas y una tercera Sesión por la tarde. Al mediodía, la Dra. Alicia Esther Ramadori (UNS) expuso su conferencia "Quien quisiere ser sabio hordene su coraçon segund el tiempo. Séneca en la literatura medieval de sentencias" y, luego, entre las 14 y las 16 hs., se desarrolló la segunda parte de los Cursos iniciados el día anterior.

A modo de Acto de Clausura, se efectuó la entrega de premios del concurso literario cuya realización elogiamos como muestra de la constante superación que se proponen los organizadores de las Jornadas y, además, celebramos que cada dos años sigan convocando a participar de este evento que se caracteriza, principalmente, por generar un fructífero diálogo científico entre investigadores de áreas afines.

Deidamia Sofia Zamperetti Martín

Universidad Nacional de La Plata

\section{BY-NC-SA}

